\title{
Role of Multiparametric MRI in Diagnosis of Prostate Cancer
}

\author{
Mathur M. ${ }^{1}$, Bains R. ${ }^{2 *}$, Kaur R. ${ }^{3}$, K. Badhan R. ${ }^{4}$, Sachin K. ${ }^{5}$, Mittal D. ${ }^{6}$ \\ DOI: https://doi.org/10.17511/ijmrr.2019.i02.13
}

\footnotetext{
1 Manoj Mathur, Professor, Department of Radiodiagnosis, Government Medical College, Patiala, Punjab, India.

2* Rohan Bains, Junior Resident, Department of Radiodiagnosis, Government Medical College, Patiala, Punjab, India.

3 Ramanpreet Kaur, Junior Resident, Department of Pathology, Government Medical College, Patiala, Punjab, India.

${ }^{4}$ Rajesh K. Badhan, Senior Resident, Department of Radiodiagnosis, Government Medical College, Patiala, Punjab, India.

5 Sachin K, Junior Resident, Department of Radiodiagnosis, Government Medical College, Patiala, Punjab, India.

6 Dimple Mittal, Junior Resident, Department of Radiodiagnosis, Government Medical College, Patiala, Punjab, India.
}

\begin{abstract}
Aims: The main objectives of our study were to evaluate the role of Multiparametric MRI (mp-MRI) in diagnosis of carcinoma prostate and to compare the various MRI sequences used in MRI in evaluating carcinoma prostate with histopathological diagnosis kept as reference standard. Materials and Methods: This prospective cross-sectional study of 40 patients was performed by using various sequences used in mp-MRI i.e. T2 weighted imaging (T2WI), Diffusion Weighted Imaging (DWI), Magnetic Resonance Spectroscopy (MRS) and Dynamic Contrast Enhanced study (DCE). Findings of mp-MRI sequences were compared with histopathological diagnosis. Statistical analysiswasperformed using SPSS computer statistical program for window release 16 . Results: Sensitivity, specificity, positive predictive value (PPV), negative predictive value (NPV) of DCE in diagnosing carcinoma prostate were $88.89 \%, 50.00 \%, 94.12 \%$ and $33.33 \%$ respectively where assensitivities, specificities, PPVs, NPVs of DWI and MRS were same in our study i.e. 94.44\%, $75.00 \%, 97.14 \%$ and $60.00 \%$ respectively. Overall sensitivity, specificity, PPV, NPV of mp-MRI by combining these sequences were found to be $97.22 \%, 75 \%, 97.22 \%$ and $75 \%$ respectively. Diagnostic accuracies of DWI, DCE and MRS were $92.5 \%, 85 \%$ and $92.5 \%$ respectively and overall diagnostic accuracy after combining these sequences in mp-MRI was $95 \%$. Conclusions: $\mathrm{mp}-\mathrm{MRI}$ including all the sequences has very good role in evaluation of carcinoma prostate. Diagnostic accuracy of $\mathrm{mp}-\mathrm{MRI}$ increases when all sequences used together to assess prostatic lesions, so all the sequences should be used together in prostate cancer evaluation rather than using individual sequences.
\end{abstract}

Keywords: T2 weighted imaging, T1 weighted imaging, Diffusion weighted imaging, Dynamic contrast enhanced imaging, MR spectroscopy

Corresponding Author

Rohan Bains, Junior Resident, Department of Radiodiagnosis, Government Medical College, Patiala, Pubjab, India.

Email: rohanbains@gmail.com
How to Cite this Article

To Browse

Mathur M, Bains R, Kaur R, Badhan RK, Sachin K, Mittal D. Role of Multiparametric MRI in Diagnosis of Prostate Cancer. Int J Med Res Rev. 2019;7(2):130138.

Available From https://ijmrr.medresearch.in/index.php/ijmrr/article/ view/1046

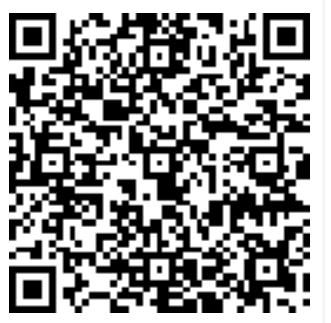




\section{Introduction}

Prostate cancer is the second most common cancer in the world among males. At present, the diagnostic pathway for prostate cancer detection is initiated on prostate specific antigen (PSA) level with digital rectal examination (DRE) followed by systematic trans-rectal ultrasound guided (TRUS) biopsy which has resulted in increased detection of prostate cancer with migration of stage toward low risk disease [1]. Multiparametric magnetic resonance imaging (mp-MRI), which is the combination of the morphological assessment of T2-weighted imaging (T2WI) with diffusion-weighted imaging (DWI), dynamic contrast-enhanced (DCE) perfusion imaging and spectroscopic imaging (MRSI), has been extensively studied in recent years[2-3].

On T2 weighted (T2W) images, the central and transitional zones cannot be distinguished and are collectively called the central gland. Central gland is separated from the peripheral zone by a thin pseudocapsule [4]. On T2W images, the peripheral zone shows high signal intensity, which is either equal to or more than that of the fat in the vicinity and the central gland displays a low or heterogeneous T2 signal intensity. Low signal intensity in the peripheral zone on T2WI is suspicious [5].

DWI uses the property of constant Brownian motion of the water molecules in tissue which is affected by increased cellularity, tissue organization, extracellular space, and integrity of cell membranes. Prostate cancer foci are visualized on DWI images as areas of restricted diffusion (high signal intensity), with corresponding low signal intensity on Apparent Diffusion Coefficient (ADC) maps [6]. During dynamic contrast enhanced (DCE) MRI, a bolus of intravenous contrast medium (gadolinium) is injected and serial, rapid sequences are obtained. The objective of DCE-MRI is to demonstrate the increased enhancement of the prostate cancer compared with normal prostatic tissue, which correlates with tumor angiogenesis. Prostate cancer typically enhances faster and to a greater extent than the surrounding prostate and will also show more rapid washout of contrast [7].

Magnetic resonance spectroscopic imaging provides information about specific metabolites with in prostatic tissue and the analysis is performed by measuring the resonance peaks of various biochemical metabolite levels such as citrate, creatine and choline.
In prostate cancer, citrate is expected to decline while choline is expected to rise. This ratio of choline and creatine to citrate is therefore indicator of malignancy [8].

Although individual imaging sequences have utility in the detection of prostate cancer, results are optimized by multiparametric ( $\mathrm{mp}$ ) MRI, which combines all of the sequences in an integrated fashion to improve specificity [9].

\section{Materials and Methods}

Setting and type of study: This cross-sectional study was carried out on 40 patients in Department of Radiodiagnosis, Government Medical College, Rajindra Hospital, Patiala who were referred to department of radiodiagnosis as suspected case of prostate cancer from clinical departments of Government Medical College, Rajindra hospital, Patiala.

\section{Inclusion Criteria}

- Patient in whom suspicion of prostate cancer was present.

- Patient giving consent for MR imaging and were willing to enroll in study.

\section{Exclusion Criteria}

- Patient having cardiac pacemaker, electromagnetic implant.

- Patient not giving consent.

\section{Equipment}

MR techniques by $1.5-\mathrm{T}$ superconductive scanner (Siemens 1.5T Magnetom Aera MRI machine)

Histopathological examination of prostatic biopsy using haemtoxylin and eosin stain

MR sequences used: Morphological imaging with standard T1 and T2 weighted imaging and advanced techniques including functional and physiological MR imaging (DWI, MRS, DCE etc) which allow extension of obtainable information beyond anatomic assessment.

\begin{tabular}{|l|l|l|l|l|l|}
\hline Parameters & $\begin{array}{c}\text { Axial } \\
\text { T1W }\end{array}$ & $\begin{array}{c}\text { T2W (Three } \\
\text { planes) }\end{array}$ & $\begin{array}{c}\text { Axial } \\
\text { DWI }\end{array}$ & $\begin{array}{c}\text { Axial 3D } \\
\text { DCE }\end{array}$ & $\begin{array}{c}\text { Axial T1 } \\
\text { post-Gd }\end{array}$ \\
\hline $\begin{array}{l}\text { Pulse } \\
\text { sequence }\end{array}$ & SPGR & FSE & EPI & SPGR & SPGR \\
\hline TR (ms) & 385 & 3,500 & 2,500 & 3.6 & 385 \\
\hline TE $(\mathrm{ms})$ & 6.2 & 102 & 65.7 & 1.3 & 6.2 \\
\hline FOV $(\mathrm{cm})$ & 16 & 16 & $18 \times 10.8$ & 26 & 16 \\
\hline ST $(\mathrm{mm})$ & 3 & 3 & 3 & 5 & 3 \\
\hline
\end{tabular}




\begin{tabular}{|l|l|l|l|l|l|}
\hline Spacing $(\mathrm{mm})$ & 0 & 0 & 0 & 0 & 0 \\
\hline Matrix & $384 \times 192$ & $384 \times 224$ & $128 \times 96$ & $256 \times 160 \times$ & $384 \times 192$ \\
& & & & 0 & \\
\hline $\begin{array}{l}\text { In-plane dimension } \\
\mathrm{b} \text { (phase [mm] } \\
\text { frequency }[\mathrm{mm}] \text { ) }\end{array}$ & $\leq 0.7 \times$ & $\leq 0.7 \times$ & $\leq 2.5 \times$ & $\leq 2 \times \leq 2$ & $\leq 0.7 \times$ \\
& & & $\leq 2.5$ & & $\leq 0.4$ \\
\hline Remarks & & & $\begin{array}{l}\text { b-values: } \\
0.500, \\
\text { and } 1,400 \\
\mathrm{~s} / \mathrm{mm} 2 \mathrm{c}\end{array}$ & $\begin{array}{l}\text { Preferred } \\
\text { temporal } \\
\text { resolution is } \\
<7 \text { seconds, }\end{array}$ & \\
& & & $\begin{array}{l}\text { total } \\
\text { observation } \\
\text { rate is }>2 \\
\text { minutes }\end{array}$ & \\
\hline
\end{tabular}

Technique- Patient were examined in supine position with proper positioning. Pelvic phased array coil was used as receiver coil for mp-MRI study of prostate. A plane localizer using three orthogonal planes were used to obtain rapid, distortion free images. Following protocols were used:-

Classical spin-echo sequences in axial, coronal and sagittal planes were used to obtain T1W images, fast spin-echo sequences were used to obtain T2W images. Rapid single shot spin-echo EPI (Echoplaner Imaging Sequence) was used to obtain DWI followed by MRS sequence. Then axial 3D DCE imaging of prostate was done by using bolus of gadolinium as contrast agent and sequential images were acquired.

\section{Results}

In present study, 40 patients were included; Mean age of patients was 68.23 years. Youngest patient in study was 50 years old and oldest was 82 years old. The mean prostate volume was $60.68 \mathrm{ml}$. All the patients included in present study had increased PSA levels with mean PSA level of $38 \mathrm{ng} / \mathrm{ml}$. In $\mathrm{mp}-$ MRI examination, peripheral zone was involved in all patients included in the study. However both peripheral zone and central gland were involved in $22(55 \%)$ patients.

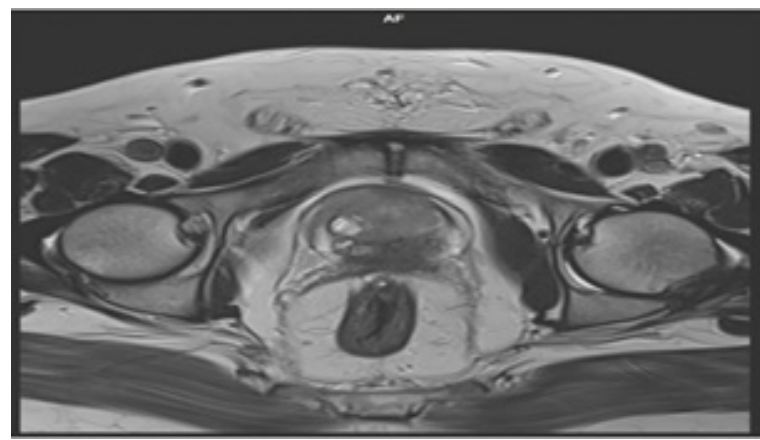

Figure-1: Axial T2WI showing hypointense lesion arising from the peripheral zone

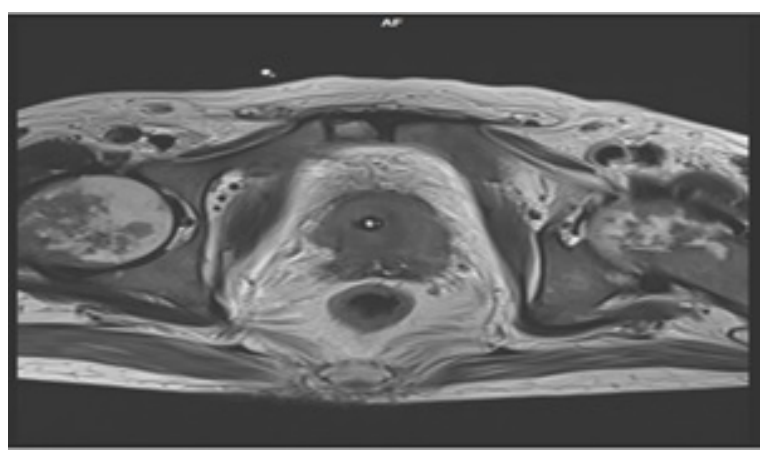

Figure-2:Axial T2WI: Hypointense area in both peripheral zone and central gland with heterogeneous signal intensity in femur head bilaterally indicative of bone metastasis

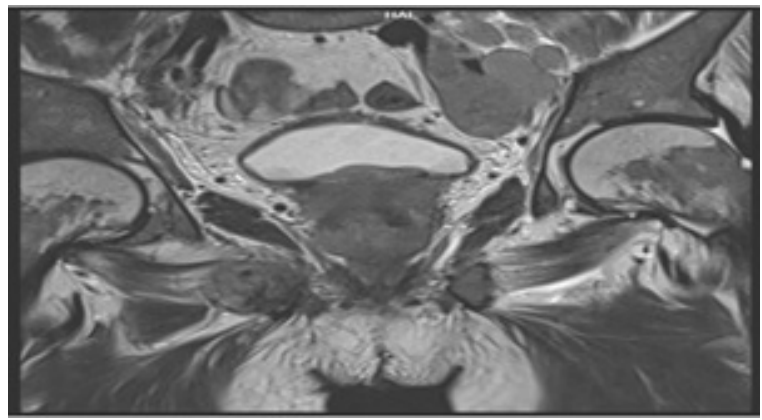

Figure-3: Coronal T2WI: extension of prostatic lesion into UB and enlarged lymph nodes

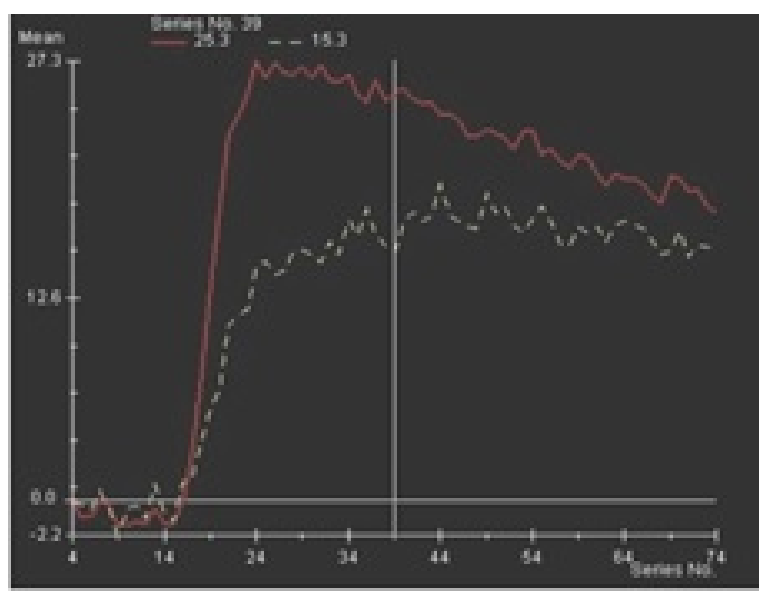

Figure-4: Dynamic contrast enhancement curve indicating early enhancement and washout of contrast in involved part of prostate 


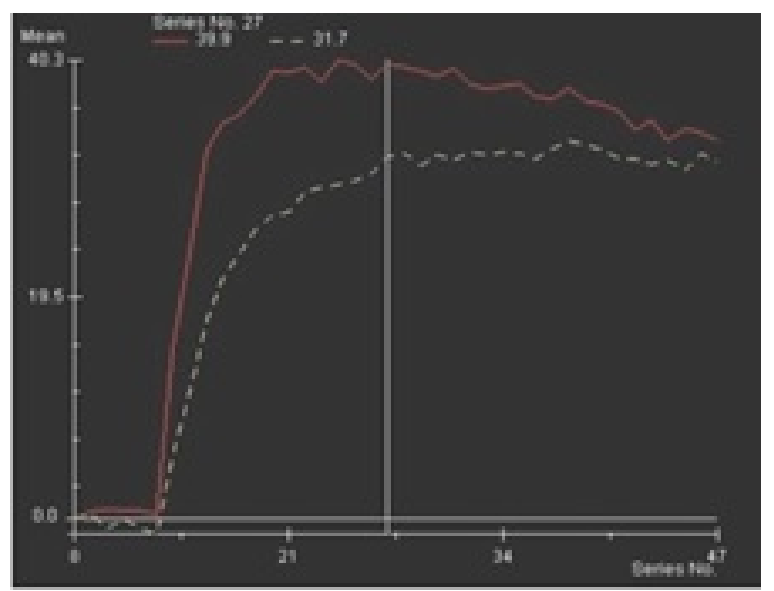

Figure-5:> Dynamic contrast enhancement curve: early uptake and wash out of contrast by tumor tissue is seen

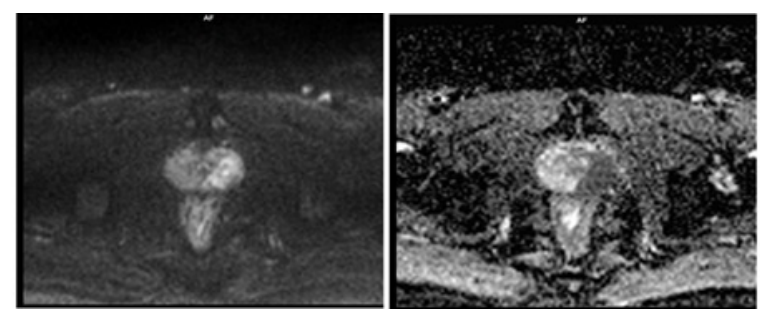

Figure-6: DWI and ADC images showing diffusion restriction in involved left part of prostate.
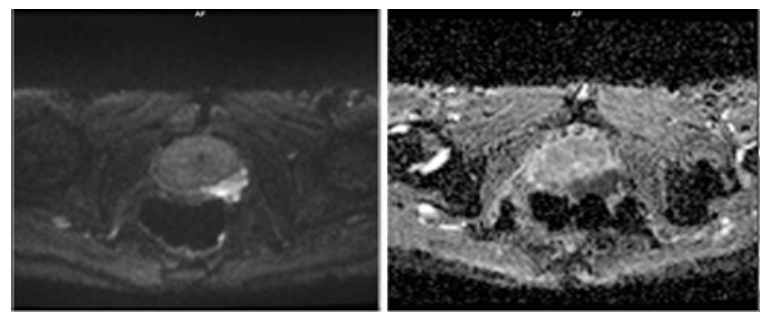

Figure-7: Lesion in left peripheral zone is showing restricted diffusion on DWI

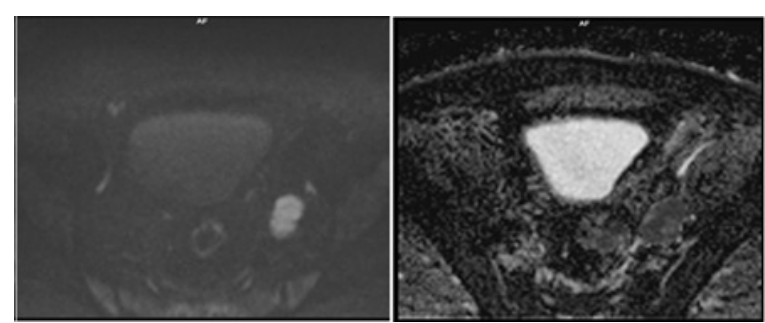

Figure-8: Metastatic lymph node on left showing restriction diffusion on DWI and ADC images.

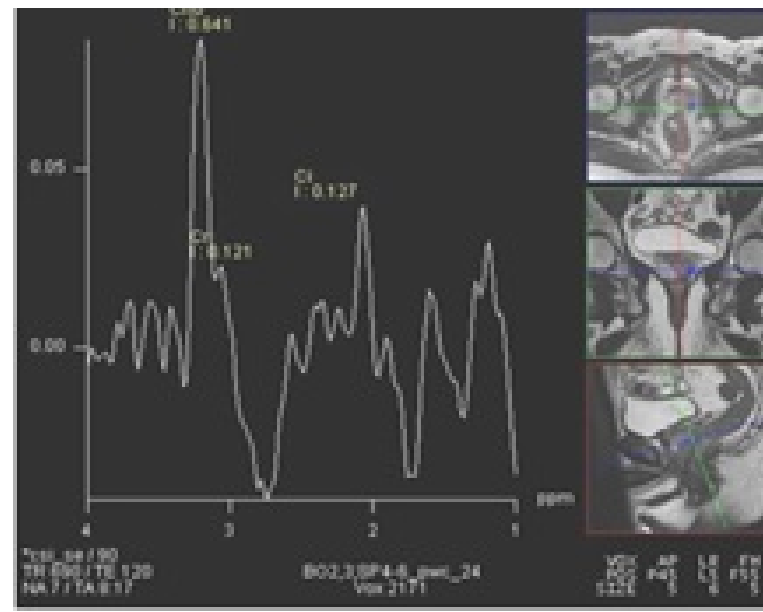

Figure-9: MRS: Increase in choline + creatine/citrate ratio in involved part of prostate indicating malignancy.

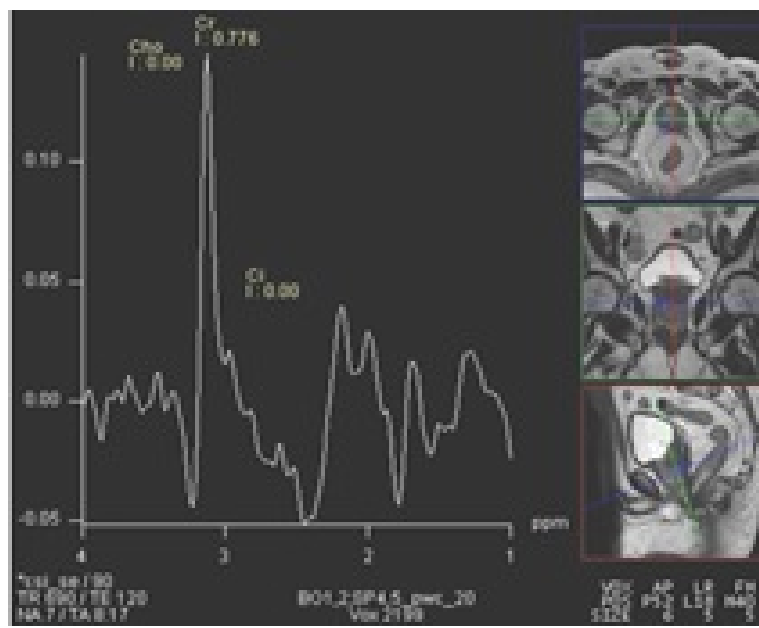

Figure-10:> MRS of involved prostate indicating increase in creatine+choline/citrate ratio indicating malignancy'

$27(67.5 \%)$ of total patients had breach in capsule and had extracapsular extension. Capsule was intact in $13(32.5 \%)$ patients. Out of total 40 patients included in study, 27 (67.50\%) patients had lesions with extraprostatic extension with involvement of Neurovascular bundles (NVB), SV (Seminal Vesicles), Urinary Bladder (UB), rectum and Obturator muscles (OM). 13 (32.5\%) patients had lesions confined to the prostate with no evidence of extraprostatic extension.6 (15\%) patients out of total 40 patients had bony metastatic lesions in $\mathrm{mp}$ MRI examination and lymph nodes were involved in $12(30 \%)$ patients. Both lymph nodal involvement and bony metastasis were observed in $6(15 \%)$ patients. 
Table-I: DCE (Dynamic Contrast Enhancement) wise Distribution of Patients.

\begin{tabular}{|l|l|l|}
\hline \multicolumn{1}{|c|}{ DCE } & \multicolumn{1}{c|}{ No. of Patients } & \multicolumn{1}{c|}{ Percentage } \\
\hline Yes & 34 & $85 \%$ \\
\hline No & 06 & $15 \%$ \\
\hline Total & 40 & $100 \%$ \\
\hline
\end{tabular}

On DCE imaging, early enhancement and washout of contrast was seen in the involved regions of prostate in $34(85 \%)$ out of total 40 (100\%) patients. Prostatic lesions in $6(15 \%)$ patients didn't show significant enhancement on DCE images as compared to normal prostate tissue.

Table-II: DWI (Diffusion Weighted Imaging) wise Distribution of Patients

\begin{tabular}{|l|l|l|}
\hline \multicolumn{1}{|c|}{ DWI } & \multicolumn{1}{c|}{ No. of Patients } & \multicolumn{1}{c|}{ Percentage } \\
\hline Yes & 35 & $87.50 \%$ \\
\hline No & 05 & $12.50 \%$ \\
\hline Total & 40 & $100 \%$ \\
\hline
\end{tabular}

Diffusion restriction was seen in involved regions of prostate on DWI in $35(87 \%)$ patients out of $40(100 \%)$. In prostatic lesions of remaining 5 $(12.5 \%)$ patients, no diffusion restriction was visualised on DWI.

Table-III: MRS (MR spectroscopy) wise Distribution of Patients.

\begin{tabular}{|l|l|l|}
\hline \multicolumn{1}{|c|}{ MRS (ch + cr/ci ratio) } & No. of Patients & \multicolumn{1}{c|}{ Percentage } \\
\hline Increased & 35 & $87.50 \%$ \\
\hline WNL & 05 & $12.50 \%$ \\
\hline Total & 40 & $100 \%$ \\
\hline
\end{tabular}

Increased $\mathrm{ch}+\mathrm{cr} / \mathrm{ci}$ ratios were observed in involved regions of prostate in $35(87.50 \%)$ patients on MRS study as compared to normal prostate tissue. Lesions in prostate of $5(12.5 \%)$ patients did not show increase in choline peak and decrease in citrate peak on MRS examination so $\mathrm{ch}+\mathrm{cr} / \mathrm{ci}$ ratios were with in normal limits in prostatic lesions.

Table-IV: Histopathological Diagnosis

\begin{tabular}{|l|l|l|}
\hline \multicolumn{1}{|c|}{ Histopathological Diagnosis } & No. of Patients & Percentage \\
\hline Adenocarcinoma & 36 & $90 \%$ \\
\hline Benign & 04 & $10 \%$ \\
\hline Total & 40 & $100 \%$ \\
\hline
\end{tabular}

In $36(90 \%)$ patients out of total 40 (100\%), lesions in prostate were histopathologically diagnosed as adenocarcinoma. Lesions in rest of the patients i.e. $4(10 \%)$ were histopathologically proved as benign lesions.

Table-V: Sensitivity, Specificity, Positive Predictive, and Negative Predictive Values of
DCE(Dynamic Contrast Enhancement) for Prostate Cancer

\begin{tabular}{|l|l|l|l|}
\hline \multirow{2}{*}{ DCE } & \multicolumn{2}{|c|}{ Histopathological Diagnosis } & \multirow{2}{*}{ Total } \\
\cline { 2 - 3 } & Adenocarcinoma & Benign & \\
\hline Present & 32 & 02 & 34 \\
\hline Absent & 04 & 02 & 06 \\
\hline Total & 36 & 04 & 40 \\
\hline
\end{tabular}

Out of total 34 patients, who displayed early enhancement and washout on DCE-MRI study of prostatic lesions, 32 were histopathologically diagnosed as adenocarcinoma and 2 were diagnosed as benign lesions. Statistical analysis was performed and sensitivity, specificity, PPV, NPV and diagnostic accuracy were calculated as $88.89 \%$, 50.00\%, $94.12 \%, 33.33 \%$ and $85 \%$ respectively.

Table-VI: Sensitivity, Specificity, Positive Predictive, and Negative Predictive Values of DWI(Diffusion weighted images) for Prostate Cancer

\begin{tabular}{|l|l|l|l|}
\hline \multirow{2}{*}{ DWI } & \multicolumn{2}{|c|}{ Histopathological Diagnosis } & \multirow{2}{*}{ Total } \\
\cline { 2 - 3 } & Adenocarinoma & Benign & \\
\hline Present & 34 & 01 & 35 \\
\hline Absent & 02 & 03 & 05 \\
\hline Total & 36 & 04 & 40 \\
\hline
\end{tabular}

Prostatic lesions of 34 (out of 35) patients, in which diffusion restriction was seen, were histopathologically diagnosed as adenocarcinoma. Histopathologically proved cancerous prostatic lesions of 2 patients did not show restricted diffusion on DWI. Sensitivity and Specificity of DWI were $94.44 \%$ and $75.00 \%$ respectively. Positive Predictive Value, Negative Predictive Value and Diagnostic accuracy were found to be $97.14 \%$, $60.00 \%$ and $92.5 \%$ respectively.

Table-VII: Sensitivity, Specificity, Positive Predictive and Negative Predictive Values of MRS (MR Spectroscopy) for Prostate Cancer

\begin{tabular}{|l|l|l|l|}
\hline \multirow{2}{*}{ MR Spectroscopy } & \multicolumn{2}{|c|}{ Histopathological Diagnosis } & \multirow{2}{*}{ Total } \\
\cline { 2 - 3 } & Adenocarinoma & Benign & \\
\hline I & 34 & 01 & 35 \\
\hline WNL & 02 & 03 & 05 \\
\hline Total & 36 & 04 & 40 \\
\hline
\end{tabular}

On MRS, 34 histopathologically diagnosed prostate cancer patients had increased $\mathrm{cr}+\mathrm{ch} / \mathrm{ci}$ ratios in prostatic lesions and only one patient with benign lesion displayed increase in $\mathrm{ch}+\mathrm{cr} / \mathrm{ci}$ ratio. Sensitivity and Specificity of DWI were $94.44 \%$ and $75.00 \%$ respectively. Positive Predictive Value, Negative Predictive Value and Diagnostic accuracy were calculated as $97.14 \%, 60.00 \%$ and $92.5 \%$ 
Respectively.

Table-VIII: Sensitivity, Specificity, Positive Predictive and Negative Predictive Values of MP-MRI for Prostate Cancer.

\begin{tabular}{|l|l|l|l|}
\hline \multirow{2}{*}{ Multiparametric MRI } & \multicolumn{2}{|c|}{ Histopathological Diagnosis } & \multirow{2}{*}{ Total } \\
\cline { 2 - 3 } & Adenocarinoma & Benign & \\
\hline Present & 35 & 01 & 36 \\
\hline Absent & 01 & 03 & 04 \\
\hline Total & 36 & 04 & 40 \\
\hline
\end{tabular}

Combined sensitivity, specificity, PPV, NPV and diagnostic accuracy for all sequences used were calculated as $97.22 \%, 75 \%, 97.22 \%, 75 \%$ and $95 \%$ respectively.

\section{Discussion}

Diagnosing and evaluating patients with carcinoma prostate in their early stage is most important in patient care and management.

Role of DCE Study in Evaluation of Prostate Cancer- DCE study is based on the tumor angiogenesis. Tumor vessels are leaky and fast exchange of blood and contrast is seen between tumor vessels and capillaries. It is interpreted on imaging as early rapid contrast enhancement followed by relatively rapid decline in cancerous tissue as compared to normal tissue. However some regions of prostate contain both malignant and benign cells so interpretation is difficult in these regions. To overcome this limitation, dynamic curve analysis of prostatic lesions is performed. Dynamic curves analysis has three components in malignant tissue i.e. rapid increase, plateau and decline. All these three components of curve are compared with the curve made on normal tissue. Tissue with more malignant component shows rapid increase and relative early decline as compared to the normal tissue[10]. Sensitivity of DCE-MRI for prostate cancer evaluation and diagnosis in present study was $88.89 \%$ which is close to sensitivity in study by Kurhanewicz et al [11] (2008) i.e. 90\%. Sensitivities of DCE-MRI in various studies compared were in range of $43 \%$ to $90 \%$. Specificity in present study is close to specificity in study by Aydin et al [12] (2012). In present study, PPV of DCE was $94.12 \%$ which is close to result in study by Kurhanewicz et al [11] (2008).

Role of DWI in Evaluation of Prostate Cancer: DWI is based on the microscopic mobility of water and its restriction by other components i.e. tissue cellularity, tissue organisation, extracellular space and cell membrane integrity.
These factors are measured by calculating apparent diffusion coefficient (ADC) from DWI. Diffusion restriction is more in tissues with high cellularity such as malignant tissues. Low ADC values are seen in tissues having malignant cells. Involved lymph nodes also show diffusion restriction on DWI. This can be interpreted on images as high signal on diffusion image and corresponding low signal on ADC maps [13]. Sensitivity of DWI in present study was $94.4 \%$ which is close to sensitivities in studies by Reinsberg et al [14], Yamamura et al [15] (2010) and Jagannathan et al [16] (2017) i.e. 93.3\%, 92\% and $89.5 \%$ respectively.In present study, the specificity of DWI for prostate cancer diagnosis was $75 \%$ which is more than specificity of DWI in studies by Reinsberg et al[14] (2007) and AbdelMaboud et al [17] (2013) i.e. $57.4 \%$ and $62 \%$ respectively, and less than specificities of DWI in other studies mentioned above. Negative predictive value (NPV) of DWI in present study was $60 \%$. Positive predictive value (PPV) of DWI for prostate cancer detection was $94.4 \%$ in study by Jagannathan et al [16] (2017) which is close to PPV of DWI in present study i.e. $97.14 \%$.

Role of MRS in Evaluation of Prostate Cancer: MRS measures the level of specific metabolites in prostate gland i.e. choline (ch), creatine (cr) and citrate (ci). Choline and citrate peaks are very close to each other and some timesits difficult to differentiate between two peaks. Concentration of ci is high in normal prostate tissue and low in malignant tissue. MRS was performed on suspicious lesions in both central gland and peripheral zone of prostate and concentrations of these metabolites were calculated [18]. We used ratio of $\mathrm{ch}+\mathrm{cr} / \mathrm{ci}$ for malignant tissue detection and ratio of more than 1 was considered significant for diagnosis of prostate cancer. Prostatitis can interfere with MRS measurements so we excluded the patients having previous history of prostatitis. Sensitivities of MRS for prostate cancer diagnosis in studies by Reinsberg et al [14] (2007) and Yamamura et al [15] (2010) were $93.3 \%$ and 92\% respectively which are very close to the sensitivity of MRS in present study ie $94.4 \%$. Specificity of MRS in study by Reinsberg et al [14] (2007) was 73.2\% and specificity of MRS in present study was $75 \%$. PPV and NPV of MRS to diagnose prostate cancer in study by Jagannathan et al [16] (2017) were 76.2\% and $40 \%$ respectively. PPV and NPV of MRS in present study were calculated as $97.1 \%$ and $60 \%$ respectively. 
Role of Multiparametric MRI (Combining all Sequences) in Evaluation of Prostate Cancer: All sequences were used at the same time for the diagnosis of mp-MRI in our study to neutralize the pitfalls of individual sequences. Sensitivity of $\mathrm{mp}-$ MRI in present study was $94 \%$ which is close to the results in above mentioned studies. Sensitivity of mp-MRI was lowest in study by Anderson et al [19] 2014 i.e. $67 \%$ and highest in study by Thestrup et al [20] (2016) i.e. 100\%. Specificities of mp-MRI in various studies were in range of $23 \%$ to $74 \%$. Specificities in studies by Tanimoto et al [21](2007) and Anderson et al [19] (2014) were $74 \%$ and $73 \%$ which are close to the results in present study i.e. $75 \%$. In studies by Abd-Alazeez et al [22] (2014), Anderson et al [19] (2014) and Jagannathan et al [16] (2017), positive predictive values (PPVs) were found to be $89 \%, 85 \%$ and $81.8 \%$. Positive predictive value of $\mathrm{mp}-\mathrm{MRI}$ in present study was $97.22 \%$. Negative predictive values (NPVs) in studies by Abd-Alazeez et al [22] (2014), Hauth et al [23] (2015), Jagannathan et al [16] (2017) and Ahmed HU [61] (2017) were 72\%, 81.9\%, 75\% and $76 \%$ respectively which are close to negative predictive value in present study i.e. $75 \%$.

\section{Conclusion}

Mp-MRI including all the sequences i.e. T2WI, DWI, MRS and DCE, has very good role in evaluation of carcinoma prostate. Sensitivity, specificity and diagnostic accuracy of DWI and MRS are more than that of DCE-MRI. Mp-MRI is very good tool in differentiating benign from malignant prostatic lesions. Sensitivity specificity and diagnostic accuracy increases when all sequences (T2WI, DWI, MRS and DCE) are used in combination so all the sequences should be used together in prostate cancer evaluation rather than using individual sequences. Various authors contributed in different ways like patient motivation, monitoring patients during MRI examination, collecting biopsy reports from pathology department and guiding the technicians in their work, example guiding them to follow proper protocol for various sequences used.

\section{What this study adds to existing knowledge}

Mp-MRI should be included in routine workup of patient suspected of carcinoma prostate and it should be conducted before biopsy to detect the site, size and extension of lesion.

\section{Source(S) of support}

1.5-T superconductive scanner (Siemens 1.5T MagnetomAera MRI machine)adolinium contrast agent from Jan Aushadhi Store Rajindra hospital Patiala

\section{Reference}

01. Siegel R, Ma J, Zou Z, Jemal A. Cancer statistics, 2014. CA Cancer J Clin. 2014;64(1)929.

[Crossref]

02. Schimmöller L, Quentin M, Arsov C, Hiester A, Buchbender $C$, Rabenalt $R$ et al. MR-sequences for prostate cancer diagnostics- validation based on the PI-RADS scoring system and targeted MR-guided in-bore biopsy. European radiology. $2014 ; 24(10) 2582-9$

[Crossref]

03. Petrillo A, Fusco R, SetolaSV,Ronza FM, Granata $V$, Petrillo $M$ et al. Multiparametric MRI for prostate cancer detection- Performance in patients with prostate-specific antigen values between 2,5 and $10 \mathrm{ng} / \mathrm{mL}$. Journal of Magnetic Resonance Imaging. 2014;39(5)1206-12. [Crossref]

04. Ravizzini G, Turkbey B, Kurdziel K, Choyke PL. New horizons in prostate cancer imaging. Eu ropean journal of radiology. 2009;70(2)212-26. [Crossref]

05. Puech $P$, Huglo D, Petyt G, Lemaitre L, Villers A. Imaging of organ-confined prostate cancerfunctional ultrasound, MRI and PET/computed tomography. Current opinion in urology. 2009;19(2)168-76.

[Crossref]

06. Gibbs P, Pickles MD, Turnbull LW. Diffusion imaging of the prostate at 3,0 tesla. Investigative radiology. 2006;41(2)185-8. [Crossref]

07. Fuchsjäger $M$, ShuklaDave $A$, Akin O, Barentsz J, Hricak H. Prostate cancer imaging. Act a Radiol. 2008;49;10720. [Crossref]

08. ZakianKL,Sircar K, Hricak H, Hui-Ni C, Dave AS, Ebehardt $S$ et al. Correlation of proton MR sp ectroscopic imaging with gleason score based on step-section pathologic analysis after radical $\mathrm{pr}$ ostatetectomy. Radiology. 2005;234(3)804-14.

[Crossref] 
09. Delongchamps NB, Rouanne M, Flam T, Benvon $F$, Literatore $M$, erbib $M$ et al. Multiparametric magnetic resonance imaging for the detection and localization of prostate cancer- combination of T2- weighted, dynamic contrast-enhanced and diffusion-weighted imaging. BJU Int. 2011;107; 1411-18.

[Crossref]

10. A Verma S, Turkbey B, Muradyan N, Rajesh. Overview of Dynamic MRI in prostate cancer diagnosis and management. AJR. 2012 Jun;198(6)1277-88.

[Crossref]

11. Kurhanewicz J, Vigneron D, Carroll P, Coakley F. Multiparametric magnetic resonance imaging in prostate cancer- present and future. Current opinion in urology. $2008 ; 18(1) 71-7$.

[Crossref]

12. Aydin H, Kizilgöz V, Tatar IG, Damar C, Ugan AR, Paker I, Hekimoğlu B. Detection of prostate cancer with magnetic resonance imagingoptimization of T1-weighted, T2-weighted, dynamic-enhanced T1-weighted, diffusionweighted imaging apparent diffusion coefficient mapping sequences and MR spectroscopy, correlated with biopsy and histopa-thological findings. J Comput Assist Tomogr. 2012;36(1)30-45.

[Crossref]

13. Tamada T, Prabhu V, Li J, Babb JS, Taneja SS, Rosenkrantz AB. Prostate cancer- diffusionweighted $M R$ imaging for detection and assessment of aggressiveness comparison between conventional and kurtosis models. Radiology. 2017 Apr 10;284(1)100-8.

[Crossref]

14. Reinsberg SA, Payne GS, Riches SF, Ashley S, Brewster JM, Morgan VA et al. Combined use of diffusion-weighted MRI and $1 \mathrm{H}$ MR spectroscopy to increase accuracy in prostate cancer detection. AJR Am J Roentgenol. 2007;188(1)91-8.

[Crossref]

15. Yamamura J, Salomon G, Buchert R, et al. MR Imaging of Prostate Cancer- Diffusion Weighted Imaging and (3D) Hydrogen 1 (1H) MR Spectroscopy in Comparison with Histology. Radiology Research and Practice. $2011 ; 616852 ; 1-9$.

[Crossref]
16. Jagannathan D, Indiran V. Accuracy of Diffusion Weighted Images and MR Spectroscopy in Prostate Lesions-Our Experience with Endorectal Coil on 1,5 T MRI. Journal of clinical and diagnostic research- JCDR. 2017;11(5)TC10.

[Crossref]

17. AbdelMaboud NM, Elsaid HH, Aboubeih EA. The role of diffusion-Weighted MRI in evaluation of prostate cancer. The Egypt J Radiol Nucl Medi. 2014;45(1)231-6.

[Crossref]

18. Kurhanewicz J, Vigneron DB. Advances in MR spectroscopy of the prostate. Magnetic resonance imaging clinics of North America. 2008 Nov 1;16(4)697-710.

[Crossref]

19. Anderson ES, Margolis DJ, Mesko S, Banerjee R, Wang PC, Demanes DJ et al. Multiparametric MRI identifies and stratifies prostate cancer lesions- implications for targeting intraprostatic targets. Brachy therapy. 2014;13(3)292-8. [Crossref]

20. Thestrup KC, Logager V, Baslev I, Møller JM, Hansen RH, Thomsen HS. Biparametric versus multiparametric MRI in the diagnosis of prostate cancer. Acta radiologica open. 2016;5(8)1-8. [Crossref]

21. Tanimoto A, Nakashima J, Kohno H, Shinmoto $\mathrm{H}$, Kuribayashi S. Prostate cancer screening- the clinical value of diffusion-weighted imaging and dynamic MR imaging in combination with T2weighted imaging. J Magn Reson Imaging. 2007;25(1)146-52.

[Crossref]

22. Abd-Alazeez M, Kirkham A, Ahmed HU, Arya M, Anastasiadis E, Charman SC et al. Performance of multiparametric MRI in men at risk of prostate cancer before the first biopsy- a paired validating cohort study using template prostate mapping biopsies as the reference standard. Prostate cancer and prostatic diseases. 2014;17(1)40-6.

[Crossref]

23. Hauth E, Hohmuth $H$, Cozub-Poetica C, Bernand $\mathrm{S}$, Beer $\mathrm{M}$, Jaeger $\mathrm{H}$. Multiparametric MRI of the prostate with three functional techniques in patients with PSA elevation before initial TRUSguided biopsy. The British journal of radiology. 2015;88(1054)20150422.

[Crossref] 
24. Ahmed HU, Bosaily AE, Brown LC, Gabe R, Kaplan R, Parmar MK et al. Diagnostic accuracy of multi-parametric MRI and TRUS biopsy in prostate cancer (PROMIS)- a paired validating confirmatory study. The Lancet. 2017;389(10071)815-22.

[Crossref] 